\title{
RP-HPLC Method Development and Validation of Synthesized Codrug in Combination with Indomethacin, Paracetamol, and Famotidine
}

\author{
Mohyeddin Assali $\mathbb{D}^{\mathbb{D}}$, Murad Abualhasan $\mathbb{D}$, Nihal Zohud $\mathbb{D}$, and Noura Ghazal \\ Department of Pharmacy, Faculty of Medicine and Health Sciences, An-Najah National University, P.O. Box 7, \\ Nablus, State of Palestine \\ Correspondence should be addressed to Mohyeddin Assali; m.d.assali@najah.edu
}

Received 24 March 2020; Revised 31 May 2020; Accepted 11 June 2020; Published 1 July 2020

Academic Editor: Antonio V. Herrera-Herrera

Copyright @ 2020 Mohyeddin Assali et al. This is an open access article distributed under the Creative Commons Attribution License, which permits unrestricted use, distribution, and reproduction in any medium, provided the original work is properly cited.

\begin{abstract}
Background. Indomethacin is considered a potent nonsteroidal anti-inflammatory drug that could be combined with Paracetamol to have superior and synergist activity to manage pain and inflammation. To reduce the gastric side effect, they could be combined with Famotidine. Methodology. A codrug of Indomethacin and Paracetamol was synthesized and combined in solution with Famotidine. The quantification of the pharmaceutically active ingredients is pivotal in the development of pharmaceutical formulations. Therefore, a novel reverse-phase high-performance liquid chromatography (RP-HPLC) method was developed and validated according to the International Council for Harmonization (ICH) Q2R1 guidelines. A reverse phase C18 column with a mobile phase acetonitrile: sodium acetate buffer $60: 40$ at a flow rate of $1.4 \mathrm{~mL} / \mathrm{min}$ and $\mathrm{pH} 5 \mathrm{was}$ utilized. Results. The developed method showed good separation of the four tested drugs with a linear range of $0.01-0.1 \mathrm{mg} / \mathrm{mL}\left(R^{2}>0.99\right)$. The LODs for FAM, PAR, IND, and codrug were $3.076 \times 10^{-9}, 3.868 \times 10^{-10}, 1.066 \times 10^{-9}$, and $4.402 \times 10^{-9} \mathrm{mg} / \mathrm{mL}$ respectively. While the LOQs were $9.322 \times 10^{-9}, 1.172 \times 10^{-10}, 3.232 \times 10^{-9}$, and $1.334 \times 10^{-8} \mathrm{mg} / \mathrm{mL}$, respectively. Furthermore, the method was precise, accurate, selective, and robust with values of relative standard deviation (RSD) less than $2 \%$. Moreover, the developed method was applied to study the in vitro hydrolysis and conversion of codrug into Indomethacin and Paracetamol. Conclusion. The codrug of Indomethacin and Paracetamol was successfully synthesized for the first time. Moreover, the developed analytical method, to our knowledge, is the first of its kind to simultaneously quantify four solutions containing the following active ingredients of codrug, Indomethacin, Paracetamol, and Famotidine mixture with added pharmaceutical inactive ingredients in one HPLC run.
\end{abstract}

\section{Introduction}

Nonsteroidal anti-inflammatory drugs (NSAIDs) are among the most consumed and prescribed drugs for both pain and inflammation worldwide [1]. Their blockage of prostaglandin synthesis by inhibiting cyclooxygenase (COX) is responsible for both the desired anti-inflammatory effects and the undesired gastrointestinal effects [2-4]. Based on COX selectivity, NSAIDs are divided into two families: nonselective NSAIDs that block both cyclooxygenase I \& II and selective cyclooxygenase II inhibitors [5-7].

Indomethacin (IND) is an example of a potent nonselective COX inhibitor that showed efficient analgesia with antipyretic and anti-inflammatory activities [8]. It is classified as an indole-acetic acid derivative according to the NSAIDs chemical classification with the chemical name of 1-( $p$-chlorobenzoyl)-5-methoxy-2-methylindole-3-acetic acid [9]. It is a poorly soluble class II compound with a half-life of $4-5 \mathrm{~h}[10,11]$. It is utilized to treat rheumatoid diseases by elevating the inflammation. Moreover, it can decrease the risk of colon cancer by providing chemoprotective effects against tumors [12, 13]. Like other NSAIDs, it appeared to have gastrointestinal, renal, and other side effects [14]. The gastric side effect could be reversed by the administration of Famotidine (FAM), which is a competitive histamine H2-receptor antagonist that 
inhibits the secretion of gastric acid and also increases collagen secretions $[15,16]$.

Recently, there has been a trend for combining NSAIDs with Paracetamol (PAR) as this often provides a synergic analgesic effect and reduces the adverse effects resulting from NSAIDs [17]. Paracetamol, $N$-acetyl- $p$-aminophenol (also known as acetaminophen), is utilized globally as an analgesic and antipyretic drug. Regarding the mechanism of action which is considered to be a weak inhibitor of the synthesis of prostaglandins (PGs), their effects in vivo are similar to these COX-2 inhibitors [18]. Although their analgesic effects are often weaker than NSAIDs, it has better tolerance, and accordingly, it is often preferred [19].

Indomethacin is considered strong and potent antiinflammatory activity against rheumatoid arthritis and other inflammatory diseases and Paracetamol is considered as the first-choice medication for both acute and chronic pain [20]. Therefore, the combination of Indomethacin with Paracetamol provides excellent anti-inflammatory and analgesic activities with a reduction of the Indomethacin side effects. Seidman and Melander reported equianalgesic activity with milder side effects upon the administration of Paracetamol with a low dose of Indomethacin in comparison to the high dose of Indomethacin alone for the treatment of rheumatoid arthritis [21]. Famotidine is considered the most potent $\mathrm{H} 2$ antagonist for the treatment of peptic ulcers and was found to be effective for prevention of Indomethacin-induced gastric injury even in the lowest dose $[22,23]$. Therefore, we aim to synthesize a novel codrug of Indomethacin and Paracetamol (IND-PAR) through a hydrolyzable ester bond combined in solution with Famotidine.

Reverse phase-high performance chromatography (RPHPLC) is considered one of the most common analytical techniques used for the development and characterization of pharmaceutical products [24, 25]. Moreover, HPLC provides a rapid, sensitive, and precise technique to separate and identify the analyzed drugs in combination or the used pharmaceutical dosage forms. Therefore, It is necessary to validate the developed HPLC method according to the International Council for Harmonization (ICH) and the United States Pharmacopeia (USP) requirements [26, 27].

Moreover, a simple and universal RP-HPLC method of analysis was developed and validated for the successful separation of a mixture containing four components: codrug, Indomethacin, Paracetamol, and Famotidine in the formulation. The developed method was used to study the hydrolysis profile of the codrug in the presence of the esterase enzyme.

\section{Materials and Methods}

2.1. Materials and Reagents. Indomethacin (IND), Famotidine (FAM), 4-(Dimethylamino) pyridine (DMAP), silica gel, and N-(3-Dimethylaminopropyl)- $\mathrm{N}^{\prime}$-ethylcarbodiimide hydrochloride (EDC) 98\% were purchased from SigmaAldrich Company. Paracetamol (PAR) was purchased from Sun Pharma Ltd. (Nablus, Palestine). Sodium acetate trihydrate, disodium hydrogen phosphate, potassium hydrogen phosphate, ethyl acetate 99.5\% (EtOAc), hexane (Hex), and dichloromethane (DCM) were purchased from CS Company, Haifa. Acetonitrile supragradient grade for chromatography $(\mathrm{ACN})$ and triethylamine $\left(\mathrm{Et}_{3} \mathrm{~N}\right)$ were purchased from SDFCL. Porcine liver esterase (PLE) was purchased from Sigma-Aldrich, USA. Inactive pharmaceutical ingredients: microcrystalline cellulose, magnesium stearate, aerosol, and Ac-Di-Sol were donated by Jerusalem Pharmaceuticals Company, Palestine.

2.2. Instrumentations. High-Performance liquid chromatography (Waters 1525, Singapore) binary HPLC pump and waters 2298 photodiode Array Detector were used. Nuclear Magnetic Resonance (NMR) spectrum was recorded on Bruker $500 \mathrm{MHz}$-Avance III, Switzerland. The high-resolution mass spectrum (HRMS) was recorded on a Shimadzu LCMS-IT-TOF utilizing ESI (+) method.

2.3. Synthesis of Indomethacin-Paracetamol (IND-PAR) Codrug. Dichloromethane $(8 \mathrm{~mL})$ was added to a mixture of Indomethacin $(200 \mathrm{mg}, 0.60 \mathrm{mmol})$, Paracetamol (101.4 mg, $0.67 \mathrm{mmol})$, EDC (128.6 mg, $0.67 \mathrm{mmol})$, and DMAP (75.1 mg, $0.62 \mathrm{mmole}$ ) and was stirred at room temperature overnight under argon. The reaction was treated with DCM and $1 \mathrm{M} \mathrm{HCl}$ three times. The collected organic layers were evaporated using a rotary evaporator. Then the crude product was purified using flash chromatography on silica gel eluted with a mobile phase of Hex: EtOAc $1: 2$ to provide a yellow solid product with a yield $70 \%(220 \mathrm{mg})$ and $R_{f}=0.63$ (Hex: EtOAc $\left.1: 2\right) .{ }^{1} \mathrm{H}$ NMR $\left(500 \mathrm{MHz}, \mathrm{CDCl}_{3}\right): \delta$ $2.11\left(\mathrm{~s}, 3 \mathrm{H}, \mathrm{COCH}_{3}\right), 2.42$ (s, 3H, $\mathrm{CH}_{3}$ indole), 3.81 (s, $3 \mathrm{H}$, $\left.\mathrm{OCH}_{3}\right), 3.86\left(\mathrm{~s}, 2 \mathrm{H}, \mathrm{CH}_{2} \mathrm{CO}\right), 6.68(\mathrm{dd}, 1 \mathrm{H}, J=9.2 \mathrm{~Hz}$, $J=2.3 \mathrm{~Hz}, \mathrm{H}-7$ indole), $6.68(\mathrm{~d}, 1 \mathrm{H}, J=9.2 \mathrm{~Hz}, \mathrm{H}-9$ indole), $6.98(\mathrm{~d}, 2 \mathrm{H}, J=8.8 \mathrm{~Hz}$, phenyl), $7.02(\mathrm{~d}, 1 \mathrm{H}, J=2.3 \mathrm{~Hz}, \mathrm{H}-6$ indole), 7.45 (dd, $4 \mathrm{H}, J=8.8 \mathrm{~Hz}, J=1.9 \mathrm{~Hz}$, phenyl), 7.65 (d, $2 \mathrm{H}, J=8.4 \mathrm{~Hz}$, phenyl). HRMS (ESI, $\mathrm{m} / \mathrm{z}$ ): calcd. for $\mathrm{C}_{27} \mathrm{H}_{24} \mathrm{~N}_{2} \mathrm{O}_{5} \mathrm{Cl}[\mathrm{M}+\mathrm{H}]^{+}$491.1374, found 491.1372.

\subsection{HPLC Analytical Method Development}

\subsubsection{Prepared Solutions}

(1) Buffer Solution pH 6.13.6 g of sodium acetate trihydrate was dissolved in $750 \mathrm{~mL}$ HPLC water, then $1 \mathrm{~mL}$ of $\mathrm{Et}_{3} \mathrm{~N}$ was added, diluted with HPLC water to $1 \mathrm{~L}$, and adjusted to $\mathrm{pH}$ 6.0 with glacial acetic acid. The mobile phase was firstly prepared using a mixture of sodium acetate Buffer:ACN, 93 : 7 [28].

(2) Diluent 1. $6.8 \mathrm{~g}$ of potassium dihydrogen phosphate was dissolved in $1 \mathrm{~L}$ HPLC water and adjusted to a $\mathrm{pH} 6.0$ using glacial acetic acid.

(3) FAM, IND, PAR, and Codrug Standard Solutions. $2.5 \mathrm{mg}$ of the standard was weighed into $25 \mathrm{~mL}$ volumetric flask; $5 \mathrm{~mL}$ methanol was added and then diluted up to $25 \mathrm{~mL}$ by the prepared diluent. 
(4) Standard Solution Mixture. $2.5 \mathrm{mg}$ of each FAM, IND, PAR, and codrug was diluted with HPLC acetonitrile to the volume $(25 \mathrm{~mL})$.

2.4.2. pH, Mobile Ratio, and Diluents Used in Method Development Trials. Different mobile phase composition, $\mathrm{pH}$, and diluents were tried throughout the analytical method development. The used mobile phases and diluents at different $\mathrm{pH}$ are summarized in Table 1.

2.5. Analytical Method Validation. The analytical method was developed according to USP and ICHQ2R1 guidelines and validated using the following parameters: linearity, range, accuracy, precision, robustness, and ruggedness [29]. All prepared parameters were in triplicates.

2.5.1. Linearity and Range. Linearity was measured by preparing a serial five concentrations in the range of $0.01-0.1 \mathrm{mg} / \mathrm{mL}$ form a preprepared stock solution of $1 \mathrm{mg} /$ $\mathrm{mL}$. The calibration curves were built by plotting the mean area under the curve (AUC) obtained from the HPLC against concentrations. The regression equation and the squared correlation coefficient $\left(R^{2}\right)$ were calculated for each ingredient curve.

2.5.2. Accuracy. Accuracy and selectivity validation parameters were calculated by preparing a standard solution of a mixture of four drugs, having a concentration of $0.24 \mathrm{mg} /$ $\mathrm{mL}$ for each drug. Three concentration levels of $80 \%, 100 \%$, and $120 \%$ of the standard concentration were made. The three solutions were prepared containing different excipients: microcrystalline cellulose, magnesium stearate, aerosol, and Ac-Di-Sol. The accuracy was evaluated by calculating the percentage of recovery.

2.5.3. Selectivity. The selectivity of the developed method was examined as the eluted peaks are well separated and not affected by any of the added excipients.

2.5.4. Precision. Precision was performed at different levels. At first, instrument precision was done by injecting the standard mixture 9 times; the \% RSD of the generated peaks of the chromatogram was calculated. An intermediate precision including interday and between analyst precision was examined on $0.08 \mathrm{mg} / \mathrm{mL}$ and $0.1 \mathrm{mg} / \mathrm{mL}$ concentration, respectively. The percentage relative standard deviation was calculated for both mixtures.

2.5.5. Robustness. The robustness of the developed method was performed by doing minor modifications on the method parameters, including detection wavelength, different mobile phase $\mathrm{pH}$, and flow rate [30]. The studied robustness parameters were the $\mathrm{pH}$ effect of the mobile phase $(4.9,5.0$, and $5.1)$, the detection wavelength $(273,275$, and $277 \mathrm{~nm})$, and the effect of the mobile phase flow rate $(1.2$, and $1.4 \mathrm{~mL} / \mathrm{min})$.
TABLE 1: Summary of method development optimization.

\begin{tabular}{lcccc}
\hline \multirow{2}{*}{ Drug } & \multicolumn{2}{c}{$\begin{array}{c}\text { Mobile } \\
\text { phase }\end{array}$} & pH & $\begin{array}{c}\text { Diluent } \\
\text { used }\end{array}$ \\
\hline & 93 & 7 & 6 & \\
Buffer & ACN & & \\
& 93 & 7 & 5 & \\
& 50 & 50 & 5.5 & Diluent 1 \\
& 60 & 40 & $5.5 \& 6$ & \\
\hline Codrug & 40 & 60 & $5.5 \& 5$ & \\
\hline \multirow{2}{*}{ PAR } & 40 & 60 & 5 & Diluent 1 \\
\hline FAM, codrug, and IND & 40 & 60 & 5 & $\begin{array}{c}\text { Methanol } \\
\text { separately }\end{array}$ \\
\hline Mixture of all drugs & 40 & 60 & 5 & ACN \\
\hline
\end{tabular}

2.5.6. Detection and Quantification Limit (LOD \& LOQ). Limit of detection (LOD) and limit of quantification (LOQ) is an indication of the analytical method sensitivity. Signal to noise ratio in the HPLC chromatogram was used to calculate these two parameters for each compound. The LOD and LOQ value of the compound was determined when the signal to noise ratio is $3: 1$ and $1: 10$, respectively.

2.6. Hydrolysis of Codrug. The synthesized codrug was incubated with an esterase enzyme to study its hydrolysis to its parent drugs (IND \& PAR). This was achieved by incubating $1 \mathrm{mg}$ of codrug into $10 \mathrm{~mL}$ phosphate buffer saline solution ( $\mathrm{pH} 7.4)$ containing $1 \mathrm{mg}$ of esterase enzyme $(10 \mathrm{U})$ at $37^{\circ} \mathrm{C}$

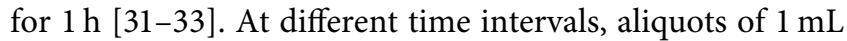
were obtained, and then the concentrations were analyzed by the developed HPLC method.

2.7. Statistical Analysis. All prepared parameters, including the in vitro hydrolysis of the codrug, were performed in triplicates. The data were expressed as means \pm relative standard deviation. Statistical analysis was performed on robustness parameters using the ANOVA test. Statistically, a significant difference was considered when the $p$ value was $<0.05$.

\section{Results and Discussion}

3.1. Synthesis of IND-PAR Codrug. Herein, we aim to synthesize a codrug of Indomethacin and Paracetamol to obtain a synergistic analgesic, antipyretic, and anti-inflammatory activities. The synthesis of the codrug was achieved through the formation of the ester bond between IND and PAR using EDC as a coupling agent and 4-(Dimethylamino)pyridine as a base, as shown in Scheme 1. The codrug was successfully synthesized with a high yield of $70 \%$. The structure of the codrug was confirmed by NMR and HRMS.

3.2. Method Development. The RP-HPLC analytical method for codrug, IND, PAR, and FAM was developed and validated according to the ICH guidelines [34]. The analytical method development was mainly based on the USP 


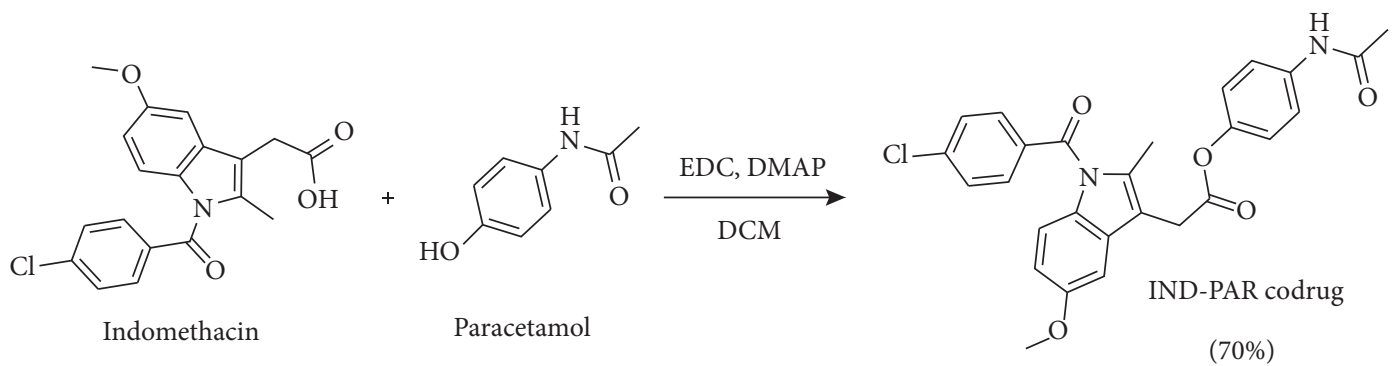

SCHeme 1: Synthetic scheme of IND-PAR codrug.

analytical method of FAM and IND and was then optimized for the best separation for the component mixture [35].

At first, FAM and IND mixture was injected using the USP analytical method for the Famotidine tablet. The produced HPLC chromatogram showed only one peak of FAM, while the IND was not eluted even after 40 minutes. The late elution of IND is probably due to its high lipophilicity and the high hydrophobicity of the used mobile phase (ACN: sodium acetate buffer 7:93). Further modification of the mobile phase $\mathrm{pH}$ was done in order to reduce the retention time of IND by making the mobile phase more acidic. Different $\mathrm{pH}$ mobile phases were tried, including 5, 5.5 , and 6 . The results showed that the most acidic $\mathrm{pH}$ mobile (pH 5) achieved early elution of IND to less than $10 \mathrm{~min}$. In order to get the best separation, the mobile phase was further optimized at different solvent compositions. Lastly, the best separation was achieved at the mobile phase composition (ACN: sodium acetate buffer $60: 40$ ). The codrug was added to the above mixture of IND and FAM using pure ACN as the diluent. The final HPLC chromatographic conditions of the developed method were by using XTERRA ${ }^{\circledR}$ MS C18, $5 \mu \mathrm{m}, 4.6 \times 250 \mathrm{~mm}$ analytical column with a flow rate of $1.4 \mathrm{~mL} / \mathrm{min}$ and a detection wavelength of $275 \mathrm{~nm}$. The operation temperature of the column was set at $25^{\circ} \mathrm{C}$. The injection volume was $10 \mu \mathrm{L}$ and the run time was 20 minutes. The developed method showed well-separated peaks for the component mixture. The resulted peaks were symmetrical with narrow broadening eluted at different retention times: 3.220, 3.624, 7.751, and $14.034 \mathrm{~min}$ for FAM, PAR, IND, and codrug, respectively, as shown in Figure 1.

\subsection{Method Validation}

3.3.1. Linearity and Range. The quality of an analytical method is profoundly dependent on the linearity of the calibration curve. The main characteristics of a calibration curve are the slope line, the regression, and the correlation.

The linearity of the method was measured by plotting the area under the curve obtained from the HPLC of each drug against the corresponding concentrations. The linearity was demonstrated over the concentration range $(0.01-0.1 \mathrm{mg} /$ $\mathrm{mL}$ ) for FAM, PAR, IND, and codrug, respectively. The obtained goodness-of-fit $\left(R^{2}\right)$ was more than 0.99 that confirms the linearity between the concentration and the area under the peak. The slopes of the regression line for FAM, PAR, IND, and codrug are shown in Figure 2.
3.3.2. Selectivity. The four drugs components (FAM, PAR, IND, and codrug) were formulated with the following inactive ingredients: microcrystalline cellulose, magnesium stearate, aerosol, and Ac-Di-Sol to study selectivity of the developed analytical method [36].

This parameter was investigated to show that there is no possible interference of the added tablet formula excipients on the separation and measurements of peak areas for the ingredient mixture (Figure 3).

3.3.3. Accuracy. The method showed great accuracy within the tested concentration range $(0.08-0.12)$. The percentage of RSD and percentage of recovery for all tested solutions are within the acceptable limits $(100 \% \pm 2 \%)$; the data are shown in Table 2.

3.3.4. Precision. The precision of a method is the degree of agreement among individual test results when the procedure is applied repeatedly to multiple samplings.

The method precision was examined at different levels; system precision was examined by injecting $0.1 \mathrm{mg} / \mathrm{mL}$ nine times on HPLC and the \% RSD was found to be less than 2.0 for all tested compounds.

The intermediate precision validation parameter at different days (intraday precision) was studied by performing three replicates measurements at two different concentrations $(0.08$ and $0.1 \mathrm{mg} / \mathrm{mL})$. The results showed that the percentage relative standard deviation of the triplicate of each concentration was less than 2.0. Moreover, the repeatability was tested for different analysts by doing three replicates measurements of the mixture at $0.12 \mathrm{mg} / \mathrm{mL}$ and the result \% RSD was also less than 2.0. The precision results at different precision levels are illustrated in Table 3.

3.3.5. Detection and Quantification Limit (LOD \& LOQ). The detection limit or LOD is the lowest amount of analyte in a sample that can be detected but not necessarily quantified. However, the limit of quantification or LOQ is the lowest amount of analyte in a sample that can be determined quantitatively with convenient precision and accuracy. The result showed that the calculated LODs for FAM, PAR, IND, and codrug were found to be $3.076 \times 10^{-9}$, $3.868 \times 10^{-10}, 1.066 \times 10^{-9}$, and $4.402 \times 10^{-9} \mathrm{mg} / \mathrm{mL}$, respectively, while the calculated LOQs were $9.322 \times 10^{-9}$, 


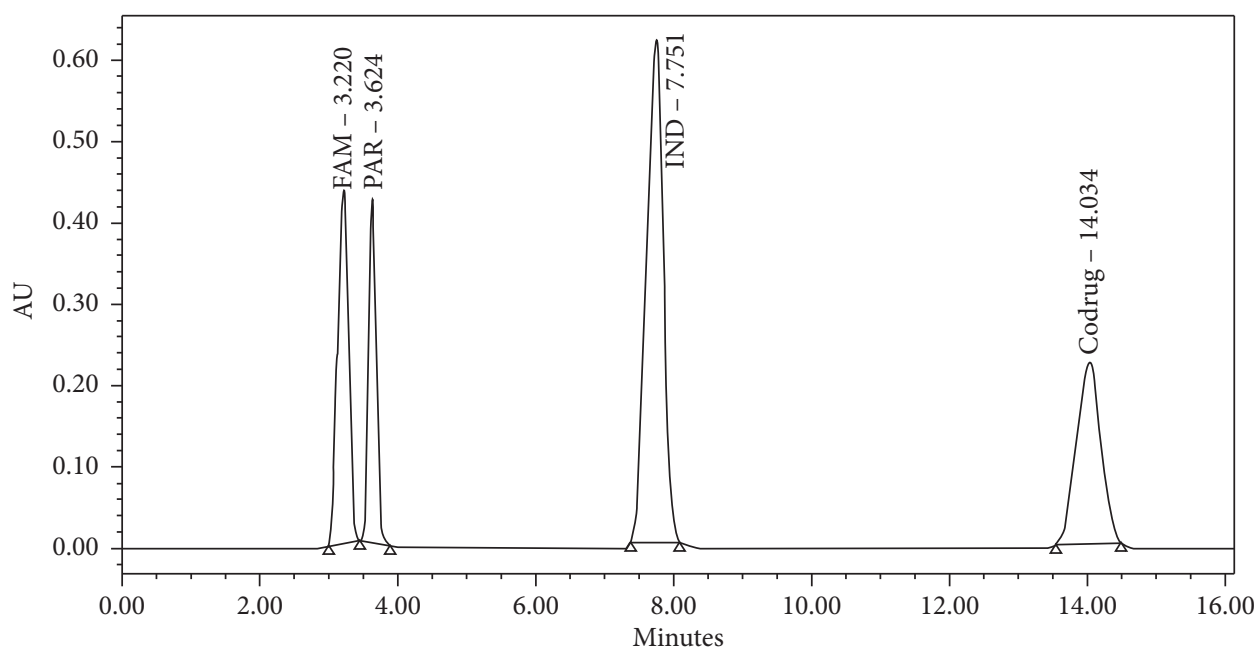

FIgURE 1: Chromatogram of the eluted peaks for the component mixture.

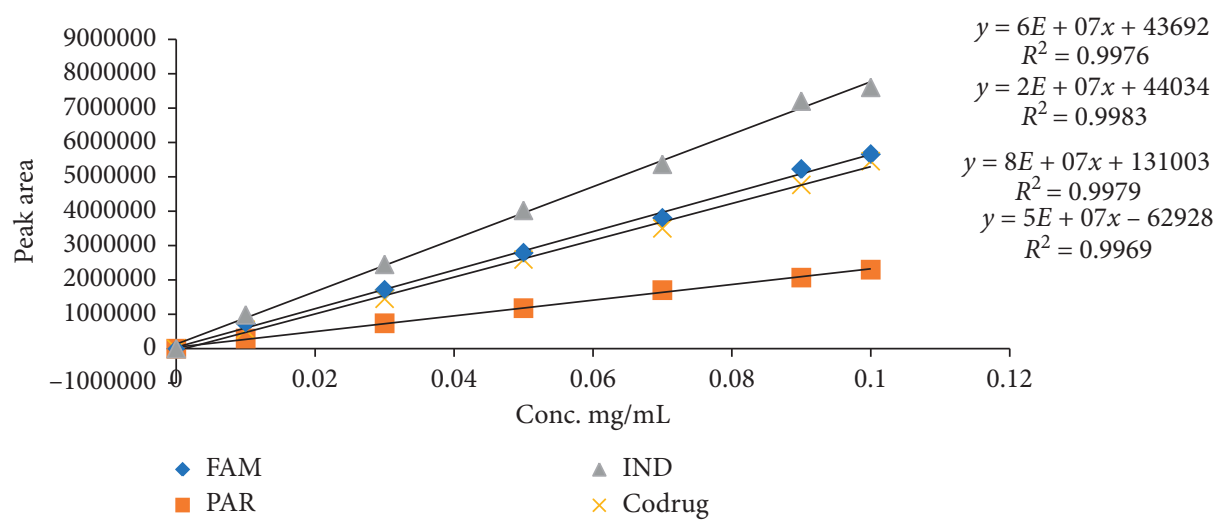

Figure 2: Linearity curves for compounds FAM, PAR, IND, and codrug.

$1.172 \times 10^{-10}, \quad 3.232 \times 10^{-9}, \quad$ and $\quad 1.334 \times 10^{-8} \mathrm{mg} / \mathrm{mL}$, respectively.

3.3.6. Robustness. Robustness is the capacity of a method to remain unaffected by minor variations in method conditions; in other words, it is a measure of the reliability of a method.

The robustness of an analytical procedure was tested by measuring its capacity of the developed method to remain unaffected by small but deliberate variations in the method parameters and providing an indication of its reliability during the normal use. For this study, the flow rate, wavelength, and $\mathrm{pH}$ parameters were changed for a mixture of $0.1 \mathrm{mg} / \mathrm{mL}$. The results are summarized in Table 4 . As can be observed, the \% RSD values in all tested and varied parameters were less than 2.0 which indicates the good robustness of the developed analytical method. Moreover, the ANOVA test shows no significant difference for the tested compounds at different robustness validation parameters ( $p$ value $>0.05)$.
3.3.7. System Suitability. System suitability tests are utilized to justify that a system is performing sufficiently to guarantee confidence in the analytical method and the obtained results. The developed method showed that all of the standard system suitability parameters, including the resolution $(R)$, the symmetry of the peaks theoretical plates $(N)$, and retention factor $(K)$, are within acceptable limits as exhibited in Figure 4 . The system suitability tests are summarized in Table 5.

An acidic mobile phase was used in the analytical method $(\mathrm{pH}=5)$ and the results of the system suitability showed good results of the tested parameters indicating the method still performs very well under the acidic $\mathrm{pH}$ conditions. Moreover, the method was tested at lower $\mathrm{pH}$ (4.9) as a part of ruggedness and robustness validation, and results were not affected by this intended lowering of the mobile phase $\mathrm{pH}$.

3.4. In Vitro Hydrolysis of Codrug. The developed analytical method was applied to investigate the in vitro conversion of the codrug to its parent drugs (IND and PAR) in the presence of esterase enzyme $(1 \mathrm{U} / \mathrm{mL})$ in $\mathrm{PBS}(\mathrm{pH} 7)$ at $37^{\circ} \mathrm{C}$. 


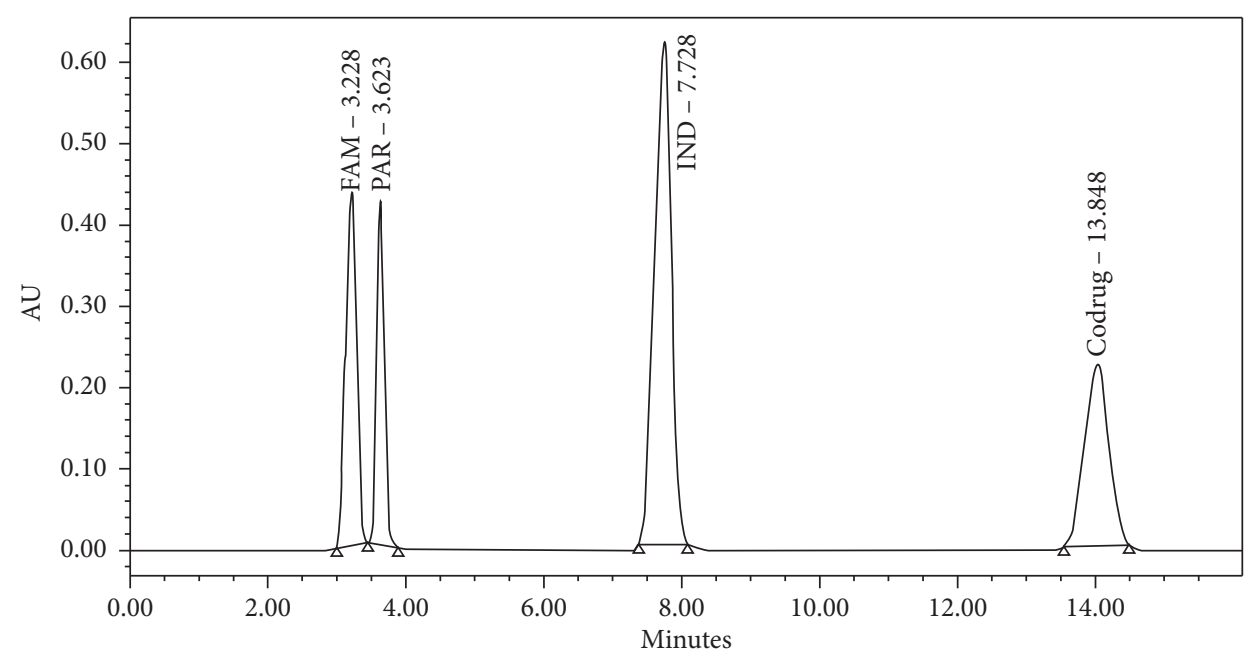

FIGURE 3: Chromatogram of the eluted peaks for the component mixture with inactive ingredients.

TABLE 2: The accuracy results in the concentration range $(0.08-0.12 \mathrm{mg} / \mathrm{mL})$.

\begin{tabular}{|c|c|c|c|c|c|}
\hline \multicolumn{2}{|c|}{ Conc. $(\mathrm{mg} / \mathrm{mL})$} & FAM & PAR & IND & Codrug \\
\hline \multirow{3}{*}{0.08} & Av. area & 3070661.67 & 1868718.67 & 6561098.33 & 3306252.67 \\
\hline & $\%$ RSD & 0.89 & 1.46 & 0.97 & 0.86 \\
\hline & \% Recovery & 99.34 & 100.76 & 100.73 & 99.5 \\
\hline \multirow{3}{*}{0.1} & Av. area & 4294603.67 & 2347628.33 & 7736858.33 & 4166430.33 \\
\hline & $\%$ RSD & 0.64 & 0.67 & 1.42 & 0.59 \\
\hline & \% Recovery & 99.5 & 99.98 & 99.22 & 101.38 \\
\hline \multirow{3}{*}{0.12} & Av. area & 5238679.0 & 2886956.67 & 9774300 & 5300362.67 \\
\hline & $\%$ RSD & 1.23 & 1.79 & 0.36 & 1.24 \\
\hline & \% Recovery & 100.33 & 100.89 & 100.88 & 100.82 \\
\hline
\end{tabular}

TABLE 3: The precision results at different precision levels.

\begin{tabular}{|c|c|c|c|c|c|}
\hline & & FAM & PAR & IND & Codrug \\
\hline \multirow{3}{*}{ System precision } & & & $0.1(\mathrm{mg} / \mathrm{mL})$ & & \\
\hline & Av. area & 4227059 & 2314677 & 7742724 & 4178095 \\
\hline & \% RSD & 0.80 & 1.66 & 1.30 & 1.64 \\
\hline \multirow{3}{*}{ Intraday precision } & & & $0.08(\mathrm{mg} / \mathrm{mL})$ & & \\
\hline & Av. area & 3147937 & 1904973 & 6560894 & 3288773 \\
\hline & \% RSD & 1.66 & 0.70 & 0.97 & 1.33 \\
\hline \multirow{3}{*}{ Interday precision } & & & $0.1(\mathrm{mg} / \mathrm{mL})$ & & \\
\hline & Av. area & 4204444 & 2317970 & 7736858 & 4098577 \\
\hline & \% RSD & 0.76 & 1.75 & 1.42 & 0.20 \\
\hline \multirow{3}{*}{ Different analyst } & & & $0.12(\mathrm{mg} / \mathrm{mL})$ & & \\
\hline & Av. area & 5249199 & 2878872 & 9739513 & 5286421 \\
\hline & \% RSD & 0.88 & 0.95 & 0.49 & 1.60 \\
\hline
\end{tabular}

Without the esterase enzyme, the codrug is stable in PBS ( $\mathrm{pH}$ 7) without the observation of any hydrolysis for one month. Upon the incubation with the esterase enzyme, a decrease in the codrug peak was observed with a concomitant increase of IND and PAR HPLC peaks, and this conversion was quantified according to the developed equations. The complete conversion was observed after 60 min with a halflife of $12.2 \mathrm{~min}$, as shown in Figure 5. 
TABLE 4: Results of the robustness at different variable parameters.

\begin{tabular}{|c|c|c|c|c|c|}
\hline & & FAM & PAR & IND & Codrug \\
\hline \multicolumn{6}{|c|}{ The wavelength of maximal absorption $\left(\lambda_{\max }\right)$} \\
\hline $273 \mathrm{~nm}$ & Av. area & 4279022 & 2357627 & 7713100 & 4191009 \\
\hline $275 \mathrm{~nm}$ & Av. area & 4225523 & 2324816 & 7797471 & 4109888 \\
\hline \multirow{2}{*}{$277 \mathrm{~nm}$} & Av. area & 4263527 & 2374482 & 7759887 & 4186203 \\
\hline & $\%$ RSD & 0.65 & 1.07 & 0.54 & 1.09 \\
\hline \multicolumn{6}{|c|}{ Mobile $\mathrm{pH}$} \\
\hline pH 5.1 & Av. area & 4353746 & 2280521 & 7609836 & 4089088 \\
\hline $\mathrm{pH} 4.9$ & Av. area & 4355659 & 2247925 & 7803400 & 4177253 \\
\hline \multirow[t]{2}{*}{ pH 5.0} & Av. area & 4225523 & 2324816 & 7797471 & 4109888 \\
\hline & $\%$ RSD & 1.73 & 1.69 & 1.42 & 1.12 \\
\hline \multicolumn{6}{|c|}{ Flow rate } \\
\hline Flow rate of $1.2 \mathrm{~mL} / \mathrm{min}$. & Av. area & 4289108 & 2336035 & 7620148 & 4220573 \\
\hline \multirow{2}{*}{ Flow rate of $1.4 \mathrm{~mL} / \mathrm{min}$. } & Av. area & 4225523 & 2324816 & 7797471 & 4109888 \\
\hline & $\%$ RSD & 1.06 & 0.34 & 1.63 & 1.88 \\
\hline
\end{tabular}

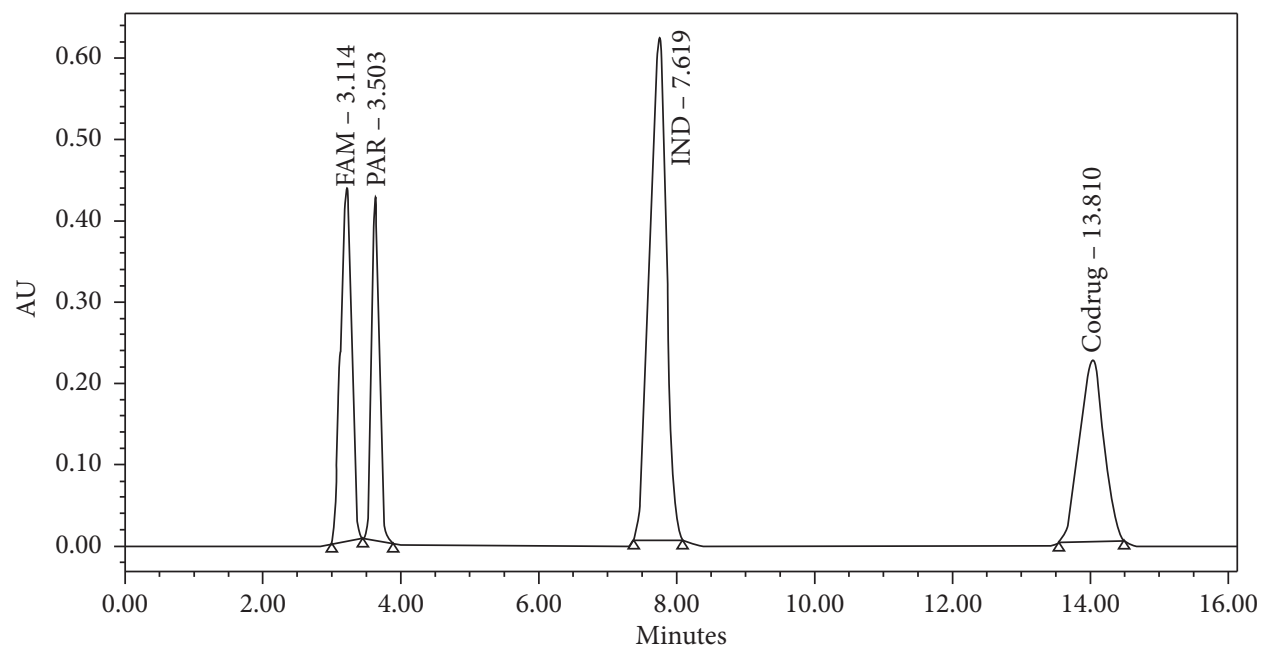

Figure 4: System suitability.

TABLe 5: System suitability.

\begin{tabular}{lcccc}
\hline & FAM & PAR & IND & Codrug \\
\hline Resolution $(R)$ & 1.2 & 6.8 & 6.7 & 7.5 \\
Symmetry of the peaks & 1.1 & 0.9 & 1.1 & 1 \\
Theoretical plates $(N)$ & 1418 & 2101 & 2160 & 6499 \\
Retention factor $(K)$ & 1.67 & 2.08 & 5.41 & 10.42 \\
\hline
\end{tabular}

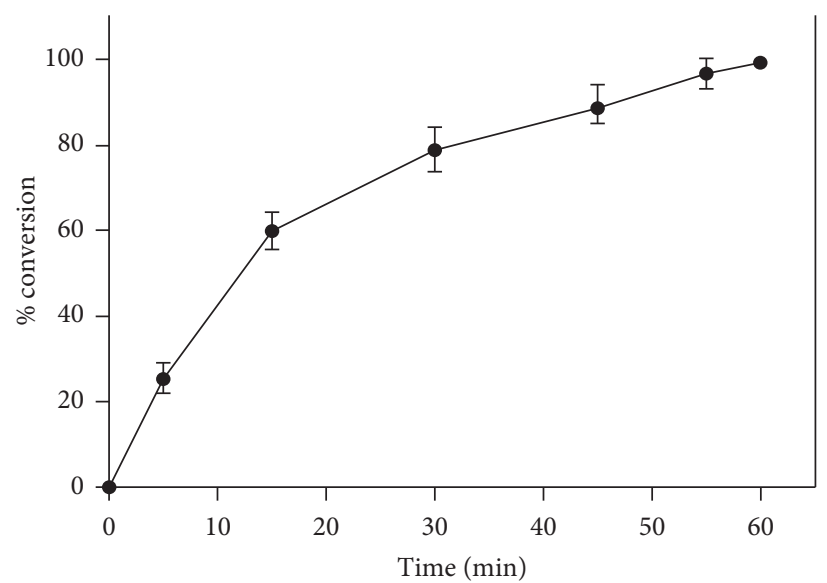

FIGURE 5: In vitro hydrolysis of codrug in the presence of esterase enzyme $(1 \mathrm{U} / \mathrm{mL})$. 


\section{Conclusion}

In this study, IND and PAR codrug was successfully synthesized. RP-HPLC method was developed and validated according to the ICH Q2R1 and USP guidelines for the successful separation of a mixture containing four components formula: FAM, PAR, IND, and codrug. The tested parameters, including linearity, accuracy, selectivity, precision, limits of detection and quantification, and robustness, were found to be within the recommended guideline ranges. Moreover, the developed method was successfully applied to quantify the in vitro hydrolysis and conversion of codrug into its parent drugs. To the best of our knowledge, this is the first study that provides an easy and direct quantification method of a combination formula of different chemical compounds (FAM, PAR, IND, and codrug).

\section{Data Availability}

The data used to support the findings of this study are included within the article.

\section{Conflicts of Interest}

The authors declare that there are no conflicts of interest regarding the publication of this paper.

\section{Acknowledgments}

The authors would like to acknowledge the Faculty of Graduate Studies (master program of pharmaceutical sciences) at An-Najah National University for facilitating the accomplishment of the current work. The research did not receive any funding. The research was performed at AnNajah National University, Palestine.

\section{References}

[1] M. C. Hochberg, R. D. Altman, K. T. April et al., "American college of rheumatology 2012 recommendations for the use of nonpharmacologic and pharmacologic therapies in osteoarthritis of the hand, hip, and knee," Arthritis Care \& Research, vol. 64, no. 4, pp. 465-474, 2012.

[2] H. Wen and K. Park, Oral Controlled Release Formulation Design and Drug Delivery: Theory to Practice, John Wiley \& Sons, Hoboken, NJ, USA, 2011.

[3] C. Sostres, C. J. Gargallo, M. T. Arroyo, and A. Lanas, "Adverse effects of non-steroidal anti-inflammatory drugs (NSAIDs, aspirin and coxibs) on upper gastrointestinal tract," Best Practice \& Research Clinical Gastroenterology, vol. 24, no. 2, pp. 121-132, 2010.

[4] K. Higuchi, E. Umegaki, T. Watanabe et al., "Present status and strategy of NSAIDs-induced small bowel injury," Journal of Gastroenterology, vol. 44, no. 9, pp. 879-888, 2009.

[5] A. Lanas, M. Boers, and J. Nuevo, "Gastrointestinal events in at-risk patients starting non-steroidal anti-inflammatory drugs (NSAIDs) for rheumatic diseases: the EVIDENCE study of European routine practice," Annals of the Rheumatic Diseases, vol. 74, no. 4, pp. 675-681, 2015.

[6] G. Sigthorsson, R. J. Simpson, M. Walley et al., "COX-1 and 2, intestinal integrity, and pathogenesis of nonsteroidal antiinflammatory drug enteropathy in mice," Gastroenterology, vol. 122, no. 7, pp. 1913-1923, 2002.
[7] M. Assali, M. Abualhasan, H. Sawaftah, M. Hawash, and A. Mousa, "Synthesis, biological activity, and molecular modeling studies of pyrazole and triazole derivatives as selective COX-2 inhibitors," Journal of Chemistry, vol. 2020, Article ID 6393428, 14 pages, 2020.

[8] K. C. Yeh, "Pharmacokinetic overview of indomethacin and sustained-release indomethacin," The American Journal of Medicine, vol. 79, no. 4, pp. 3-12, 1985.

[9] E. Fritsche, S. J. Baek, L. M. King, D. C. Zeldin, T. E. Eling, and D. A. Bell, "Functional characterization of cyclooxygenase-2 polymorphisms," Journal of Pharmacology and Experimental Therapeutics, vol. 299, no. 2, pp. 468-476, 2001.

[10] J.-L. Ziltener, S. Leal, and P.-E. Fournier, "Non-steroidal antiinflammatory drugs for athletes: an update," Annals of Physical and Rehabilitation Medicine, vol. 53, no. 4, pp. $278-288,2010$.

[11] S. Clarysse, D. Psachoulias, J. Brouwers et al., "Postprandial changes in solubilizing capacity of human intestinal fluids for BCS class II drugs," Pharmaceutical Research, vol. 26, no. 6, pp. 1456-1466, 2009.

[12] O. Gallo, A. Franchi, L. Magnelli et al., "Cyclooxygenase-2 pathway correlates with VEGF expression in head and neck cancer. Implications for tumor angiogenesis and metastasis," Neoplasia, vol. 3, no. 1, pp. 53-61, 2001.

[13] A. M. Farrag, "Synthesis and biological evaluation of novel indomethacin derivatives as potential anti-colon cancer agents," Archiv der Pharmazie, vol. 349, no. 12, pp. 904-914, 2016.

[14] H. Matsui, O. Shimokawa, T. Kaneko, Y. Nagano, K. Rai, and I. Hyodo, "The pathophysiology of non-steroidal anti-inflammatory drug (NSAID)-induced mucosal injuries in stomach and small intestine," Journal of Clinical Biochemistry and Nutrition, vol. 48, no. 2, pp. 107-111, 2011.

[15] A. Perez-Aisa, F. Sopeña, E. Arceiz, J. Ortego, R. Sainz, and A. Lanas, "Effect of exogenous administration of transforming growth factor-beta and famotidine on the healing of duodenal ulcer under the impact of indomethacin," Digestive and Liver Disease, vol. 35, no. 6, pp. 397-403, 2003.

[16] M. A. Hassan, M. S. Salem, M. S. Sueliman, and N. M. Najib, "Characterization of famotidine polymorphic forms," International Journal of Pharmaceutics, vol. 149, no. 2, pp. 227232, 1997.

[17] C. K. Ong, R. A. Seymour, P. Lirk, and A. F. Merry, "Combining paracetamol (acetaminophen) with nonsteroidal antiinflammatory drugs: a qualitative systematic review of analgesic efficacy for acute postoperative pain," Anesthesia \& Analgesia, vol. 110, no. 4, pp. 1170-1179, 2010.

[18] G. G. Graham and K. F. Scott, "Mechanism of action of paracetamol," American Journal of Therapeutics, vol. 12, no. 1, pp. 46-55, 2005.

[19] G. G. Graham, M. J. Davies, R. O. Day, A. Mohamudally, and K. F. Scott, "The modern pharmacology of paracetamol: therapeutic actions, mechanism of action, metabolism, toxicity and recent pharmacological findings," Inflammopharmacology, vol. 21, no. 3, pp. 201-232, 2013.

[20] A. N. Zaid, M. N. Abualhasan, N. Jaradat, M. Marar, K. Mansoor, and F. Qa'dan, "Development and validation of a new analytical HPLC method for the estimation of carvone in suppositories," Journal of Pharmaceutical Investigation, vol. 46, no. 2, pp. 557-563, 2016.

[21] P. Seideman and A. Melander, "Equianalgesic effects of paracetamol and indomethacin in rheumatoid arthritis," Rheumatology, vol. 27, no. 2, pp. 117-122, 1988. 
[22] W. Schunack, "What are the differences between the H2receptor antagonists?" Alimentary Pharmacology \& Therapeutics, vol. 1, pp. 493s-503s, 2007.

[23] Y. Naito, S. Iinuma, N. Yagi et al., "Prevention of indomethacin-induced gastric mucosal injury in helicobacter pylori-negative healthy volunteers: a comparison study rebamipide vs famotidine," Journal of Clinical Biochemistry and Nutrition, vol. 43, no. 1, pp. 34-40, 2008.

[24] P. K. Sahu, N. R. Ramisetti, T. Cecchi, S. Swain, C. S. Patro, and J. Panda, "An overview of experimental designs in HPLC method development and validation," Journal of Pharmaceutical and Biomedical Analysis, vol. 147, pp. 590-611, 2018.

[25] M. Assali, R. Shawahna, S. Dayyeh, M. Shareef, and I.-A. Alhimony, "Dexamethasone-diclofenac loaded polylactide nanoparticles: preparation, release and anti-inflammatory activity," European Journal of Pharmaceutical Sciences, vol. 122, pp. 179-184, 2018.

[26] I. H. T. Guideline, "Text on validation of analytical procedures," in International Conference on Harmonization, Geneva, Switzerland, 1994.

[27] I. S. Committee, "ICH harmonised tripartite guidelines. Validation of analytical procedures: methodology Q2," in Proceedings of the International Conference on Harmonisation of Technical Requirements for Registration of Pharmaceuticals for Human Use, Geneva, Switzerland, 1996.

[28] USP-36, Buffer solutions in united strates pharmacopea, second supplement to USP36-NF31, p. 6244, 2013.

[29] P. Ravisankar, C. N. Navya, D. Pravallika, and D. N. Sri, "A review on step-by-step analytical method validation," IOSR Journal of Pharmacy, vol. 5, no. 10, pp. 7-19, 2015.

[30] M. N. Abualhasan, "A validated stability-indicating HPLC method for routine analysis of an injectable lincomycin and spectinomycin formulation," Scientia Pharmaceutica, vol. 80, no. 4, pp. 977-986, 2012.

[31] M. Assali, M. Joulani, R. Awwad et al., "Facile synthesis of ciprofloxacin prodrug analogues to improve its water solubility and antibacterial activity," ChemistrySelect, vol. 1, no. 6, pp. 1132-1135, 2016.

[32] M. Assali, N. Kittana, S. A. Qasem et al., "Combretastatin A4camptothecin micelles as combination therapy for effective anticancer activity," RSC Advances, vol. 9, no. 2, pp. 10551061, 2019.

[33] M. Assali, A. N. Zaid, N. Kittana, D. Hamad, and J. Amer, "Covalent functionalization of SWCNT with combretastatin A4 for cancer therapy," Nanotechnology, vol. 29, no. 24, Article ID 245101, 2018.

[34] ICH, Guideline, ICH harmonized tripartite: validation of analytical procedures: text and methodology, 2005.

[35] M. Abualhasan, M. Ghanem, M. Assali, and A. Zaid, "The effect of non-compliance of PPI instruction on the stability of reconstituted oral antibiotics," Journal of Applied Pharmaceutical Science, vol. 5, no. 8, pp. 143-146, 2015.

[36] M. Abualhasan, M. Assali, N. Jaradat, and T. Sarhan, "Synthesis, formulation and analytical method validation of rutin derivative," Letters in Drug Design \& Discovery, vol. 16, no. 6, pp. 685-695, 2019. 